\title{
PENGARUH PROMOSI DAN HARGA TERHADAP KEPUTUSAN PEMBELIAN PADA HOUSE OF SHOPAHOLIC DI BANDAR LAMPUNG
}

\author{
Desi Derina Yusda, SE.,MM ${ }^{1)}$ \\ D III Manajemen Industri - Universitas Mitra Indonesia \\ Jl. Z.A Pagar Alam No. 7, Gedong Meneng Bandar Lampung, 0721788960 \\ desiderina@umitra.ac.id
}

\begin{abstract}
ABSTRAK
Tujuan dari penelitian ini adalah untuk menguji dan menganalisis pengaruh promosi dan harga terhadap keputusan pembelian pada House of Shopaholic di Bandar Lampung. Populasi dalam penelitian ini adalah konsumen yang berkunjung pada House of Shopaholic di Bandar Lampung dengan jumlah sampel sebanyak 198 responden menggunakan teknik pengambilan sampel incidential, pengumpulan data primer menggunakan kuesioner dan pengumpulan data sekunder menggunakan studi pustaka dan dokumentasi. Pengujian hipotesis dalam penelitian ini menggunakan regresi linear berganda. Secara simultan, promosi, dan harga berpengaruh signifikan terhadap keputusan pembelian konsumen pada House of Shopaholic. Secara parsial, promosi berpengaruh signifikan terhadap keputusan pembelian konsumen pada House of Shopaholic di Bandar Lampung dan harga berpengaruh signifikan terhadap keputusan pembelian konsumen pada House of Shopaholic di Bandar Lampung. Koefisien determinasi yang diperoleh sebesar 52,3\% yang menunjukkan bahwa promosi dan harga memiliki kemampuan untuk menjelaskan keputusan pembelian, sedangkan sisanya 47,7\% dapat dijelaskan oleh variabel atau faktor lain yang tidak diteliti dalam penelitian ini.
\end{abstract}

Kata Kunci: keputusan pembelian, promosi, harga

\section{PENDAHULUAN}

Perkembangan tren fashion di Indonesia didorong oleh banyak faktor diantaranya yang saat ini popular adalah internet dan media sosial. Fashion dan wanita merupakan dua hal yang tidak terpisahkan antara satu dengan yang lainnya. Setiap wanita ingin tampil gaya dan terlihat menarik dan cantik. Karena itu wanita sangat identik dengan baju, sepatu, tas sampai perhiasan dengan model terbaru yang menarik perhatian para wanita. Yaitu wanita sangat ingin terlihat cantik dan fashionable karena wanita dan kecantikan adalah dua hal yang tidak terpisahkan.

Bandar lampung adalah kota yang sedang berkembang yang mana penjualan baju, tas dan sepatu tidak hanya di dapat di mall atau di toko-toko tradisional karena saat ini mulai bergeser pada model transaksi online. Dengan berkembangnya teknologi konsumen lebih dimanjakan, karena konsumen dapat melihat dan melakukan transaksi tanpa harus ke mall ataupun toko tradisional. Dengan adanya media internet dan media sosial konsumen sudah dapat melihat model-model baju, sepatu dan tas terbaru dan langsung melakukan transaksi pembelian via online.

Dalam mempengaruhi keputusan pembelian, konsumen tidak bisa lepas dari bauran pemasaran. Bauran pemasaran (marketing mix) menurut Kottler (2012:18) adalah seperangkat alat pemasaran yang digunakan perusahaan untuk terus-menerus mencapai tujuan pemasarannya di pasar sasarannya. House of Shopaholic merupakan sebuah toko retail baju yang memulai usahanya dari toko kecil dan berjualan online. Dalam hal ini House of Shopaholic menjual semua fashion bagi perempuan. House of Shopaholic di dalam strategi bisnis yang selama ini digunakan dalam menjalankan usahanya lebih mengutamakan promosi dan harga karena strategi promosi House of Shopaholic adalah melalui media sosial (online) dan harga yang kompetitif dibandingkan toko yang lain. Untuk menarik minat konsumen membeli produk yang ditawarkan maka House of Shopaholic gencar menerapkan adanya promosi di media sosial yang efektif, harga yang kompetitif dibandingkan harga yang ditawarkan pesaing. Promosi merupakan variabel dari pemasaran yang bertujuan untuk menginformasikan mengenai keadaan produk, menarik minat konsumen, membujuk dan mengingatkan terhadap suatu produk. Setelah melihat adanya promosi yang menarik, maka dengan sendirinya konsumen akan mencoba membandingkan harga yang ditawarkan oleh House of Shopaholic tersebut dibandingkan dengan harga yang ditawarkan oleh pesaing. Menurut Setiadi (2010:331) Harga yang kompetitif akan mempengaruhi konsumen untuk memilih produk tersebut dibandingkan produk yang ada di pasaran lainnya.

Alasan selanjutnya penelitian ini menggunakan variabel promosi, karena promosi adalah cara penjual menawarkan suatu produk dengan cara memberikan rangsangan supaya konsumen ingin membeli. Apalagi saat ini, daya beli konsumen yang rendah akibat kenaikan - kenaikan harga menjadikan promosi menjadi cara yang tepat dalam mempengaruhi keputusan pembelian konsumen, selain hal tersebut, promosi memberikan rangsangan langsung kepada konsumen dan konsumen dapat merasakan manfaat langsung dari promosi penjualan yang penjual lakukan ke konsumen. Sehingga dapat mempengaruhi 
keputusan pembelian konsumen secara lebih cepat. Hal tersebut juga di dukung dengan penelitian terdahulu yang menyatakan bahwa semakin gencar perusahaan dalam melakukan kegiatan promosi maka akan membuat konsumen dapat dipengaruhi dan tertarik untuk membelinya (Doni, 2013).

Selain promosi, dengan adanya harga yang kompetitif maka konsumen juga bisa memilih mana harga yang sesuai dengan kondisi keuangan pembeli, secara tidak langsung pembeli itu dapat menentukan berapa biaya yang dikeluarkan untuk berlangganan, dan mungkin pembeli bisa meminimalisir sedikit pengeluarannya. Hal tersebut di perkuat dengan penelitian terdahulu yang menyatakan bahwa semakin menarik harga yang ditawarkan dalam pembelian produk maka akan semakin dapat meningkatkan keputusan konsumen untuk membeli produk (Susanto, 2013).

Dilihat dari penjelesan tersebut, dapat dikatakan bahwa promosi dan harga dapat menjadi pertimbangan bagi konsumen untuk mengambil keputusan pembelian dimana media promosi menyajikan segala hal informasi tentang produk fashion House of Shopaholic , sedangkan harga menjadi peritimbangan bagi konsumen apakah sesuai dengan kemampuan atau tidaknya konsumen tersebut melakukan pembelian. Jika kedua fitur tersebut dapat terpenuhi konsumen pun dapat mengambil keputusan dalam membeli produk House of Shopaholic.

Berdasarkan uraian di atas penulis tertarik untuk mengadakan penelitian dengan judul "Pengaruh Promosi dan Harga terhadap Keputusan Pembelian pada House of Shopaholic di Bandar Lampung”

\section{PEMBAHASAN}

\section{Analisis Regresi Linier Berganda}

Dalam penelitian ini, untuk menguji hipotesis dianalisis dengan menggunakan regresi linier berganda. Analisis ini digunakan untuk mengetahui besarnya pengaruh variabel-variabel bebas (independen) yaitu promosi dan harga terhadap variabel terikat (dependen) yaitu keputusan pembelian. Berikut adalah persamaan regresi Linear Berganda:

$$
\mathrm{Y}=\alpha+\beta 1 \mathrm{X} 1+\beta 2 \mathrm{X} 2+e
$$

Keterangan:

$\begin{array}{ll}\mathrm{Y} & =\text { Keputusan Pembelian } \\ \alpha & =\text { Konstanta } \\ \beta 1-\beta 2 & =\text { Koefisien Regresi } \\ \mathrm{X} 1 & =\text { Promosi } \\ \mathrm{X} 2 & =\text { Harga } \\ e & =\text { Standar Error }\end{array}$

\section{Pengujian Validitas}

Menurut Syofian Siregar (2015:56) validitas adalah menunjukkan sejauh mana suatu alat ukur mampu mengukur apa yang diukur. Uji validitas dilakukan untuk mengukur pernyataan yang ada dalam kuesioner. Validitas suatu data tercapai jika pernyataan tersebut mampu mengungkapkan apa yang akan diungkapkan. Uji validitas dilakukan dengan mengkorelasikan masing-masing pernyataan dengan jumlah skor untuk masing-masing variabel. Untuk mempercepat dan mempermudah penelitian ini pengujian validitas dilakukan dengan bantuan komputer dengan menggunakan software SPSS forwindows.

\section{Uji Reliabilitas}

Menurut Syofian Siregar (2015:56) reabilitas bertujuan untuk mengetahui sejauh mana hasil pengukuran tetap konsisten apabila dilakukan pengukuran dua kali atau lebih terhadap gejala yang sama dengan menggunakan alat ukur yang sama pula. Pengujian reliabilitas menggunakan internal consistency dengan alat ukur Alpha Conbrach dengan bantuan computer melalui program SPSS. Dengan pengambilan keputusan sebagai berikut :

Cronbach's Alpha >06, maka pernyataan dinyatakan reliabel.

Cronbach's Alpha < 0.6, maka pernyataan dinyatakan tidak tidak reliabel. 


\section{Uji Reliabilitas}

Uji Validitas

Tabel. 2.2

Uji Validitas Instrumen Variabel X dan Y

\begin{tabular}{|l|c|l|l|}
\hline $\begin{array}{l}\text { Item } \\
\text { Pernyataan }\end{array}$ & $\begin{array}{l}\text { Corrected } \\
\text { Item-Total } \\
\text { Correlation }\end{array}$ & $\begin{array}{l}\text { R } \\
\text { table }\end{array}$ & Validitas \\
\hline Variabel X1 (Promosi) & \multicolumn{5}{|l|}{} \\
\hline Q1 & 0,750 & 0.361 & Valid \\
\hline Q2 & 0,853 & 0.361 & Valid \\
\hline Q3 & 0,529 & 0.361 & Valid \\
\hline Q4 & 0,613 & 0.361 & Valid \\
\hline Q5 & 0,853 & 0.361 & Valid \\
\hline Variabel X2 (Harga) & \multicolumn{5}{|l}{} \\
\hline Q6 & 0,683 & 0.361 & Valid \\
\hline Q7 & 0,867 & 0.361 & Valid \\
\hline Q8 & 0,855 & 0.361 & Valid \\
\hline Q9 & 0,450 & 0.361 & Valid \\
\hline Q10 & 0,573 & 0.361 & Valid \\
\hline Variabel Y (Keputusan Membeli) & \\
\hline Q11 & 0,750 & 0.361 & Valid \\
\hline Q12 & 0,701 & 0.361 & Valid \\
\hline Q13 & 0,500 & 0.361 & Valid \\
\hline Q14 & 0,705 & 0.361 & Valid \\
\hline Q15 & 0,517 & 0.361 & Valid \\
\hline
\end{tabular}

Sumber: Hasil Pengolahan SPSS 24 (2017)

Berdasarkan Tabel 2.2 diatas menunjukkan bahwa seluruh pernyataan instrumen variabel independent adalah valid, hal ini dapat dilihat dari $\mathrm{r}_{\text {hitung }}$ output nilai korelasi antara tiap item dengan skor total item pada keseluruhan pernyataan lebih besar dari $r_{\text {tabel, }}$ variabel independent dapat digunakan untuk penelitian. (0.361), sehingga 15 pernyataan variabel independent dapat digunakan untuk penelitian.
Tabel 2.3.

Uji Instrumen Reabilitas Variabel XY

\begin{tabular}{|l|l|l|l|}
\hline $\begin{array}{l}\text { Item } \\
\text { Pernyataan }\end{array}$ & $\begin{array}{l}\text { Cronbach's } \\
\text { Alpha }\end{array}$ & $\begin{array}{l}\text { Nilai } \\
\text { batasan }\end{array}$ & Reabilitas \\
\hline X1 & 0,881 & 0.06 & Realibel \\
\hline X2 & 0,874 & 0.06 & Realibel \\
\hline Y & 0,823 & 0.06 & Realibel \\
\hline
\end{tabular}

Sumber : Hasil Pengolahan SPSS 24 (2017)

Berdasarkan Tabel 2.3 diatas dapat diketahui bahwa nilai Cronbach Alpha dari seluruh variabel yang diujikan nilainya sudah diatas 0,6 maka dapat disimpulkan bahwa seluruh variabel dalam penelitian ini dalam uji reliabilitas dinyatakan reliabel.

\section{Analisis Regresi Linier Berganda}

Tabel 2.4

Coefficients ${ }^{\text {a }}$ Regresi

\begin{tabular}{|c|c|c|c|c|c|}
\hline \multicolumn{6}{|c|}{ Coefficients $^{\mathrm{a}}$} \\
\hline \multirow[b]{2}{*}{ Model } & \multicolumn{2}{|c|}{$\begin{array}{l}\text { Unstandardize } \\
\text { d Coefficients }\end{array}$} & $\begin{array}{l}\text { Standar } \\
\text { dized } \\
\text { Coeffici } \\
\text { ents }\end{array}$ & \multirow[b]{2}{*}{$\mathrm{t}$} & \multirow[b]{2}{*}{ Sig. } \\
\hline & B & $\begin{array}{l}\text { Std. } \\
\text { Error }\end{array}$ & Beta & & \\
\hline \begin{tabular}{|l|l}
1 & $\begin{array}{l}\text { (Consta } \\
\text { nt) }\end{array}$
\end{tabular} & 6.314 & 1.040 & & 6.072 & .000 \\
\hline $\begin{array}{l}\text { Promos } \\
\text { i }\end{array}$ & .274 & .062 & 293 & 4.390 & .000 \\
\hline Harga & .457 & .065 & .471 & 7.055 & .000 \\
\hline
\end{tabular}

Sumber: Hasil Pengolahan SPSS 24 (2017)

$\mathrm{Y}=\mathrm{a}+\mathrm{b}_{1} \mathrm{X}_{1}+\mathrm{b}_{2} \mathrm{X}_{2}+\mathrm{e}$

Persamaan regresi $Y=6,314+0,274 \mathrm{X}_{1}+0,457+\mathrm{e}$

Dari persamaan regresi linier berganda diatas, dapatdiuraikan sebagai berikut:

a. Konstanta adalah 6,314. Artinya perubahan keputusan pembelian (Y) pada saat semua variabel bebasnya nol (0) adalah 6,314.

b. Koefisien regresi promosi nilainya sebesar 0,274 artinya apabila terjadi peningkatan pada promosi $\left(\mathrm{X}_{1}\right)$ setiap 1 satuan, maka keputusan pembelian (Y) meningkat sebesar 0,274satuan.

c. Koefisien regresi harga nilainya sebesar 0,457 artinya apabila terjadi peningkatan padaharga $\left(\mathrm{X}_{2}\right)$ setiap 1 satuan, maka keputusan pembelian (Y) meningkat sebesar 0,457 satuan. 


\section{Uji Koefisien Secara Simultan (Uji F)}

Tabel 2.5

Tabel Anova

\begin{tabular}{|c|c|c|c|c|c|}
\hline \multicolumn{6}{|l|}{$\mathrm{ANOVA}^{\mathrm{a}}$} \\
\hline Model & $\begin{array}{l}\text { Sum of } \\
\text { Squares }\end{array}$ & $\mathrm{df}$ & \begin{tabular}{|l} 
Mean \\
Square
\end{tabular} & $\mathrm{F}$ & Sig. \\
\hline \begin{tabular}{|l|l}
1 & $\begin{array}{l}\text { Regres } \\
\text { sion }\end{array}$
\end{tabular} & 766.097 & 2 & 383.049 & $\begin{array}{l}90.9 \\
55\end{array}$ & $.000^{\mathrm{b}}$ \\
\hline $\begin{array}{l}\text { Residu } \\
\text { al }\end{array}$ & 821.221 & 195 & 4.211 & & \\
\hline Total & $\begin{array}{l}1587.31 \\
8\end{array}$ & 197 & & & \\
\hline \multicolumn{6}{|c|}{ a. Dependent Variable: Keputusan Pembelian } \\
\hline \multicolumn{6}{|c|}{ b. Predictors: (Constant), Harga, Promosi } \\
\hline
\end{tabular}

Sumber: Hasil Pengolahan SPSS 24 (2017)

Pada Tabel 2.5 nilai $F$ hitung adalah 90,955 dimana Fhitung > Ftabel, yaitu 90,955> 3.04 dengan dengan tingkat signifikansi sebesar 0,000 $<0,05$. Ini berarti Ha diterima artinya variabel independen (promosi dan harga) secara serempak (simultan) berpengaruh signifikan terhadap keputusan pembelian.

\section{Uji Koefisien Secara Parsial (Uji t)}

Tabel 2.6

Tabel Coefficients $\mathbf{t}$

\begin{tabular}{|c|c|c|c|c|c|c|}
\hline \multicolumn{7}{|c|}{ Coefficients $^{\mathrm{a}}$} \\
\hline \multirow{2}{*}{\multicolumn{2}{|c|}{ Model }} & \multicolumn{3}{|c|}{\begin{tabular}{|l|l|} 
Unstandardi & Standardiz \\
ed \\
zed & Coefficien \\
Coefficients & ts
\end{tabular}} & \multirow[t]{2}{*}{ 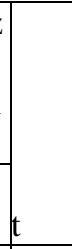 } & \multirow[b]{2}{*}{ Sig. } \\
\hline & & B & $\begin{array}{l}\text { Std. } \\
\text { Error }\end{array}$ & Beta & & \\
\hline \multirow[t]{3}{*}{1} & (Constant) & $\begin{array}{l}6.3 \\
14\end{array}$ & 1.040 & & $\begin{array}{l}6.07 \\
2 \\
\end{array}$ & .000 \\
\hline & Promosi & $\begin{array}{l}.27 \\
4\end{array}$ & .062 & .293 & $\begin{array}{l}4.39 \\
0\end{array}$ & .000 \\
\hline & Harga & $\begin{array}{l}.45 \\
7\end{array}$ & .065 & .471 & $\begin{array}{l}7.05 \\
5\end{array}$ & .000 \\
\hline
\end{tabular}

a. Dependent Variable: Keputusan Pembelian

Sumber: Hasil Pengolahan SPSS 24 (2017).

Berdasarkan tabel 2.6 dapat diketahui bahwa:

Hasil uji t untuk variabel promosi diperoleh nilai $\mathrm{t}_{\text {hitung }}=4,390$ dengan tingkat signifikansi 0,000 . Dengan menggunakan batas signifikansi 0,05, didapat $t_{\text {tabe }} l$ sebesar 1,652. Ini berarti $t_{\text {hitung }}>t_{\text {tabel }}(4,390>1,652$ ), makaHo ditolak dan $\mathrm{Ha}$ diterima.Atau dengan melihat tingkat signifikansinya yaitu tingkat signifikansi $<0,05(0,000<0,05)$ maka Ho ditolak dan Ha diterima. Dengan demikian maka promosi memiliki pengaruh positif dan signifikan terhadap kepuasan konsumen.

Hasil uji t untuk variabel harga diperoleh nilai $t_{\text {hitung }}=7,055$ dengan tingkat signifikansi 0,000 . Dengan menggunakan batas signifikansi 0,05, didapat $t_{\text {tabe }} l$ sebesar 1,652. Ini berarti $t_{\text {hitung }}>t_{\text {tabel }}(7,055>1,652$ ), maka Ho ditolak dan Ha diterima. Atau dengan melihat tingkat signifikansinya yaitutingkat signifikansi $<0,05(0,000<0,05)$ maka Ho ditolak dan diterima. Dengan demikian maka harga memiliki pengaruh positif dan signifikan terhadap kepuasan konsumen.

\section{Uji Koefisien Determinasi (Uji $\mathbf{R}^{2}$ ) \\ Tabel 2.7}

Hasil R Square

\begin{tabular}{|l|l|l|l|l|l|}
\hline \multicolumn{5}{|l|}{ Model Summary } \\
\hline
\end{tabular}

Berdasarkan hasil Tabel 2.7 diketahui bahwa analisis regresi menghasilkan $\mathrm{R}$ Square sebesar 0,523. Hal ini berarti keputusan pembelian dapat dipengaruhi oleh variabel promosi dan harga sebesar 52,3\% sedangkan sisa nya sebesar $47,7 \%$ dipengaruhi faktor lain yang tidak diteliti dalam penelitian.

\section{Pengaruh Variabel Promosi (X1) Terhadap Keputusan pembelian (Y)}

Berdasarkan uji signifikansi parsial dan uji secara serentak, variabel promosi berpengaruh secara positif dan signifikan terhadap keputusan pembelian, artinya jika variabel promosi ditingkatkan maka keputusan pembelian juga akan meningkat. Konsep iklan yang mudah dimengerti akan membuat konsumen tertarik untuk selalu melihat aktivitas promosi yang dilakukan oleh House of Shopaholic . Konsumen mendapatkan informasi mengenai House of Shopaholic melalui iklan, publisitas, promo penjualan, maupun personal selling. Semakin tinggi intensitas promosi dan diimbangi dengan iklan yang mudah dimengerti maka akan semakin memberikan dampak positif terhadap keputusan pembelian konsumen pada House of Shopaholic.

\section{Pengaruh Variabel Harga (X2) Terhadap Keputusan Pembelian (Y)}

Berdasarkan uji signifikansi parsial dan uji secara serentak, variabel Harga berpengaruh secara positif dan signifikan terhadap keputusan pembelian, artinya jika ditingkatkan variabel harga sebesar satu satuan maka keputusan pembelian akan meningkat pula. Harga yang murah dan sesuai dengan kemampuan konsumen menjadi faktor pendorong bagi konsumen untuk 
berkujung pada House of Shopaholic. Jika harga pada House of Shopaholic lebih murah dari toko lain, maka pembeli akan memperhatikan hargapada House of Shopaholic dibanding toko lain. Dengan penilaian tersebut maka konsumen akan tetap berkeinginan untuk melakukan pembelian pada House of Shopaholic dengan memperhatikan harganya.

\section{Pengaruh Variabel Promosi (X1) dan Harga (X2) Terhadap Keputusan Pembelian (Y)}

Berdasarkan uji signifikansi uji secara serentak, variabel promosi dan harga berpengaruh secara positif dan signifikan terhadap keputusan pembelian, artinya jika variabel promosi dan harga ditingkatkan maka keputusan pembelian juga akan meningkat. Promosi yang mudah dimengerti dan menarik serta harga yang murah dan sesuai dengan kemampuan konsumen menjadi faktor pendorong bagi konsumen untuk berkujung pada House of Shopaholic. Jika promosi lebih menarik dengan model dan desaign produk yang kekinian dan harga pada House of Shopaholic lebih murah dari dari toko lain, maka pembeli akan terus memperhatikan promosi dan harga dalam melakukan pembelian pada toko House of Shopaholic.

\section{KESIMPULAN}

Berdasarkan hasil analisis yang telah dilakukan, maka peneliti dapat mengambil beberapa kesimpulan sebagai berikut :

Berdasarkan hasil uji signifikansi variabel bebas yaitu promosi dan harga secara bersama-sama atau serempak berpengaruh signifikan terhadap variabel terikat yaitu keputusan pembelian. Berdasarkan hasil penelitian ini maka diketahui bahwa variabel bebas memiliki pengaruh yang kuat terhadap variabel terikat. Hasil pengujian hipotesis secara parsial menunjukan bahwa variabel promosi berpengaruh positif dan signifikan terhadap keputusan pembelian pada House of Shopaholic dan variabel paling dominan adalah variabel harga dalam mempengaruhi keputusan pembelian konsumen pada House of Shopaholic .

Hasil pengujian hipotesis secara parsial menunjukan bahwa variabel harga berpengaruh positif dan signifikan terhadap keputusan pembelian pada House of Shopaholic .

Berdasarkan perhitungan koefisien determinasi $\left(\mathrm{R}^{2}\right)$, maka diperoleh nilai Adjusted $\mathrm{R}$ Square sebesar 0,523 . Angka ini menjelaskan bahwa sebesar 52,3\%. Keputusan pembelian pada House of Shopaholic dipengaruhi oleh variabel bebas (promosi dan harga). Sedangkan sisanya sebesar $47,7 \%$ dipengaruhi faktorfaktor lain yang tidak diteliti dalam penelitian ini seperti lokasi, pelayanan dan lain-lain.

Berdasarkan hasil penelitian yang diperoleh dari data-data dilapangan, adapun saran yang penulis ajukan sebagai berikut:

Variabel promosi pada House of Shopaholic sebaiknya lebih ditingkatkan, sehingga House of Shopaholic lebih dikenal oleh calon konsumen dan mampu meningkatkan penjualan House of Shopaholic, sehingga fungsi promosi bagi House of Shopaholic, yaitu untuk memasarkan produk House of Shopaholic dapat dilakukan secara maksimal. Selain itu disarankan agar menampilkan iklan-iklan yang menarik dan mudah dimengerti oleh masyarakat. Hal ini bertujuan agar masyarakat dapat menerima maksud dan tujuan dari aktivitas promosi itu sendiri.

Berdasarkan hasil penelitian, variabel harga berpengaruh secara positif dan signifikan terhadap variabel keputusan pembelian. Pengelolaan terhadap kualitas dan manfaat sesuai dengan harga harus tetap dilakukan secara berkelanjutan dan lebih optimal, karena hal ini sangat mempengaruhi keputusan konsumen dalam memilih dan membeli produk baju wanita dengan design modern dan harga yang terangkau.

Mengingat keterbatasan yang dimiliki oleh penulis, diharapkan untukpeneliti selanjutnya dapat lebih menyempurnakan penelitian ini misalnya dengan menambah variabel-variabel lain dalam penelitian.

\section{Daftar Pustaka}

[1] Agus, Susanto. 2013. Pengaruh Promosi, Harga dan Inovasi Produk Terhadap Keputusan Pembelian Pada Batik Tulis Karangmlati. Universitas Negeri Semarang.

[2] Doni Hariadi,2013. Pengaruh Harga, Produk, dan Promosi, dan Distribusi Terhadap Keputusan Pembelian Konsumen Pada Produk Projector Microvision, Jurnal Ilmu dan Riset Manajemen, Vol 1 Nomer 1, Januari 2013, Hal 67-87, Sekolah Tinggi Ilmu Ekonomi Indonesia (STIESIA) Surabaya.

[3] Kotler, Philip and Gary Amstrong. Prinsip Prinsip Pemasaran. Edisi 13. Jilid 1. Jakarta : Erlangga. 2012

[4] Setiadi, Nugroho. Perilaku Konsumen : Perspektif Kontemporer pada Motif, Tujuan, dan Keingina Konsumen, Jakarta: Kencana Prenada Media. 2010

[5] Siregar, Syofian. Statistik Parametrik : Untuk Penelitian Kuantitatif. Jakarta : Sinar Graafika Offset.2015 